\title{
ATIVIDADE DA UREASE EM LATOSSOLOS SOB INFLUÊNCIA DA COBERTURA VEGETAL E DA ÉPOCA DE AMOSTRAGEM(1)
}

\author{
Regina Márcia Longo(2) \& Wanderley J osé de Melo(3)
}

\begin{abstract}
RESUMO
O presente trabalho teve por objetivo avaliar o efeito do tipo de vegetação e da época de amostragem na atividade da urease em dois diferentes solos tropicais. O experimento foi instalado em Latossolo Vermelho Aluminoférrico típico e Latossolo Vermelho distrófico típico sob cinco diferentes culturas: pinus, eucalipto, citrus, soja e milho. As amostragens de solo foram efetuadas mensalmente, de abril de 1990 a março de 1991, determinando-se a atividade da urease, o N-total e o C-orgânico. A atividade da urease variou de acordo com a época de amostragem, apresentando valores mais elevados nos meses mais quentes e úmidos. A cobertura vegetal influenciou a conversão de $\mathbf{N}$-uréia a $\mathbf{N}$ $\mathrm{NH}_{4}$, observando-se maior atividade da urease nas amostras de solo sob pinus e eucalipto, embora, no início do ciclo das culturas da soja e do milho, a atividade da urease também tenha sido elevada.
\end{abstract}

Termos de indexação: urease, Latossolos, C-orgânico, N-total.

\section{SUMMARY: UREASE ACTIVITY IN OXISOLS AS INFLUENCED BY VEGETATION COVER AND SAMPLING TIME}

The present study ai med to eval uate the effect of the vegetation type and the sampling time on urease activity in two different tropical soils (Rhodic Oxisols). Theexperiment was installed in a typic alumino-ferric Red Latossol and a typic distrophic Red Latosol under five different vegetations: pinus, eucalypt, citrus, soybean and corn. The soil samples were collected from April 1990 to March 1991 and the ureaseactivity, total nitrogen and organic carbon were determined. The urease activity changed according to the sampling time,

(1) Recebido para publicação em junho de 2000 e aprovado em fevereiro de 2005.

(2) Engenheira-Agrônoma e Doutora em Engenharia de Água e Solo pela Universidade de Campinas - UNICAMP. Estrada da Rhodia, 5555, cs 91, Barão Geraldo, CEP 13085-850 Campinas (SP). Email: rmlongo@uol.com.br

(3) Professor Titular do Departamento de Tecnologia, Universidade Estadual Paulista - UNESP/J aboticabal. Via de Acesso Prof. Paulo Donato Castellane s/n, CEP 14884-900 J aboticabal (SP). Email: wjmelo@fcav.unesp.br 
presenting higher values in the warmer and humid months. The vegetation type affected the conversion of $\mathrm{N}$-urea to $\mathrm{N}-\mathrm{NH}_{4}{ }^{+}$, with higher urease activity being observed in the soil under pinus and eucalypt, although the activity was high at the beginning of the soybean and corn cropping cycle.

Index terms: urease, Oxisols, organic C, total $\mathrm{N}$.

\section{INTRODUÇÃO}

Em sistemas agrícolas, os fertilizantes nitrogenados são amplamente utilizados para suprir as necessidades das plantas, sendo a uréia um dos fertilizantes mais utilizados.

A uréia vem sendo empregada com grande sucesso como fertilizante nitrogenado, mas, ocasionalmente, produz resultados insatisfatórios, o que se deve, dentre outros fatores, à volatilização da amônia. As perdas de amônia decorrem do fato de que a uréia sofre uma hidrólise enzimática no solo, produzindo carbonato de amônio, que se desdobra facilmente em $\mathrm{NH}_{3}$ e $\mathrm{CO}_{2}$ (Rodrigues \& Kiehl, 1986).

No solo, a uréia é rapidamente hidrolisada pela ação da urease, afetando a utilização desse importante fertilizante nitrogenado. Sua ocorrência é grande em plantas e microrganismos (particularmente as bactérias) e tem sido detectada na mucosa gástrica do homem e de alguns animais. Sua presença em sol o foi primeiro indicada por Rotini (1935), seguido dos trabalhos de Conrad (1940a,b; 1942a,b, 1943), evidenciando que os solos continham urease e que esta enzima era a responsável pela conversão da uréia em amônia.. Trabalhos recentes sobre a determinação da atividade da urease no sol o foram realizados por Klose \& Tabatabai, 1999; Benini et al., 1999.

Dentre os fatores que afetam a atividade enzimática do solo, destacam-se a concentração do substrato, o nível de umidade, temperatura e pH do solo (Santos et al., 1991; Silva et al., 1995; Arunachalan \& Melkania, 1999). Em condições tropicais, pouco se conhece sobre a atividade da urease no solo e os fatores que a afetam.

O tipo de vegetação e a quantidade do material orgânico incorporado influenciam a atividade da urease (Pancholy \& Rice, 1972; Silva et al., 1995; Arunachalam \& Melkania, 1999). Palma \& Conti (1990) observaram que, em sol os sob vegetação de eucal ipto, há al ta concentração de lignina e celulose no material orgânico incorporado, o que pode provocar mudanças na comunidade de microrganismos do solo, acarretando mudanças na atividadeenzimática. SegundoSantos et al. (1991), a vel oci dade dehidrólise da uréia ébastantealterada pelo tipo de vegetação, sendo as amostras colhidas sob a vegetação de pinus no Latossolo Roxo as que apresentaram a menor capacidade de hidrolisar a uréia. Deacordo com Bremner \& Mulvaney (1978), desde que os solos contenham urease proveniente demicrorganismos, a atividade enzimática podeser aumentada pela adição de gl i cose ou outro material que promova incremento na atividade microbiana. OToole et al. (1982), Longo et al. (1993) e Deng \& Tabatabai (1996), observaram não só a correlação positiva entre a atividade da urease, C-orgânico e $\mathrm{N}$-total do solo, mas também a diminuição progressiva nos valores da atividade da urease com o decréscimo da temperatura do solo.

Outro aspecto a ser considerado é o efeito da época de amostragem. Palma \& Conti (1990) observaram um aumento na atividade enzimática durante o verão e decréscimo durante o inverno. Essas observações concordam com os resultados obtidos por Ross et al. (1984) que obtiveram baixa atividade da urease sob vegetação natural durante o inverno. Sttot \& Hagedorn (1980) observaram aumento na atividade da urease durante a primavera e o verão e declínio durante o inverno.

Neste contexto, o presente trabalho teve por objetivo avaliar o efeito do tipo de vegetação e da época de amostragem na atividade da urease, em dois tipos de solos tropicais (Latossolo Vermelho Aluminoférrico típico e Latossolo Vermelho distrófico).

\section{MATERIAL E MÉTODOS}

O experimento foi realizado em área experimental pertencente à Faculdade de Ciências Agrárias e Veterinárias / UNESP, campus de J aboticabal (SP), em Latossol o Vermel ho Aluminoférricotípico (LVaf) e Latossolo Vermelho distrófico (LVd) (Embrapa, 1999), sendo coletadas amostras de solo sob pinus, eucali ipto, citrus, soja e milho (Quadro 1).

O experimento utilizou parcelas subdivididas com quatro repetições, num delineamento experimental inteiramente casualisado, com cinco tratamentos principais de cobertura vegetal e 12 subtratamentos (amostragens mensais durante um ano).

As culturas perenes (pinus, eucalipto e citrus) já se encontravam instaladas nos dois solos. As culturas anuais (milho e soja) foram instaladas em dezembro de 1990, após aração e gradagem, em outubro do mesmo ano. As amostragens realizadas no período anterior a essa data foram feitas com o 
Quadro 1. Análise de fertilidade dos solos sob cultivo de soja, milho, pinus, eucalipto e citrus ${ }^{(1)}$

\begin{tabular}{|c|c|c|c|c|c|c|c|c|c|c|c|}
\hline Solo & Cultura & $\mathbf{P}$ & мо & $\mathrm{pH} \mathrm{CaCl} 2$ & $\mathbf{K}^{+}$ & $\mathrm{Ca}^{2+}$ & $\mathbf{M g}^{2+}$ & $\mathbf{H}+\mathbf{A l}$ & $\mathbf{s}$ & $\mathbf{T}$ & $\mathbf{v}$ \\
\hline & & $\mathrm{mg} \mathrm{dm}^{-3}$ & $\mathrm{~g} \mathrm{~kg}^{-1}$ & & & & $-\mathrm{mmc}$ & $\mathrm{c} \mathrm{dm}^{-3}$ & & - & $\%$ \\
\hline \multirow[t]{5}{*}{ Lvaf } & Soja & 18 & 19 & 5,3 & 2 & 28 & 1,3 & 28 & 43 & 71 & 61 \\
\hline & Milho & 26 & 19 & 5,3 & 2 & 31 & 1,3 & 25 & 46 & 71 & 65 \\
\hline & Pinus & 6 & 19 & 4,3 & 2 & 11 & 0,5 & 42 & 18 & 60 & 10 \\
\hline & Eucalipto & 8 & 30 & 4,6 & 3 & 27 & 0,9 & 52 & 39 & 91 & 43 \\
\hline & Citrus & 31 & 19 & 4,4 & 3 & 21 & 0,3 & 47 & 27 & 74 & 37 \\
\hline \multirow[t]{5}{*}{ LVd } & Soja & 53 & 14 & 6,7 & 2 & 40 & 2,4 & 12 & 66 & 78 & 85 \\
\hline & Milho & 57 & 12 & 6,6 & 2 & 45 & 2,6 & 12 & 73 & 85 & 86 \\
\hline & E ucalipto & 6 & 14 & 4,2 & 1 & 10 & 0,3 & 34 & 14 & 48 & 29 \\
\hline & Citrus & 4 & 19 & 3,9 & 2 & 5 & 0,2 & 47 & 9 & 56 & 16 \\
\hline & Citrus & 38 & 19 & 4,9 & 3 & 25 & 0,9 & 34 & 37 & 71 & 52 \\
\hline
\end{tabular}

('1) Raij et al. (1987).

LVaf: Latossolo Vermelho Aluminoférrioco típico; LVd: Latossolo Vermelho distrófico típico.

solo descoberto. No plantio, as culturas foram adubadas com as fórmulas 15-30-20 e 0-04-20, respectivamente, sendo também realizada na área de milho uma adubação de cobertura com sulfato de amônio. O espaçamento utilizado para o milho foi de 1,0 m e, para a soja, de 0,6 m.

As áreas foram divididas em quatro parcelas de $6 \times 10 \mathrm{~m}$ para fins de amostragem de solo, sendo essas real izadas, mensalmente, de abril/90 a março/ 91. Em cada parcela, foram obtidas 20 amostras simples, coletadas com um trado, na profundidade de $0-20 \mathrm{~cm}$, formando uma amostra composta por área útil das parcelas. As amostras de solo foram secas ao ar e então peneiradas $(1 \mathrm{~mm})$ e armazenadas em sacos de pol ietileno, atéo momento das análises.

Nas amostras de solo coletadas, foram determinados atividade da urease, carbono orgânico, nitrogênio total, $\mathrm{pH}$ e umidade.

A taxa de hidrólise da uréia, que é função da atividade da urease, foi determinada seguindo o método de May \& Douglas (1976), modificado por Longo et al. (1991). Para o sol o seco ao ar, tomaramse $3,0 \mathrm{~g}$, adicionando-se $0,5 \mathrm{~mL}$ detoluenoe $12,0 \mathrm{~mL}$ de água deionizada; em seguida, procedeu-se à incubação a $30^{\circ} \mathrm{C}$ por $10 \mathrm{~min}$ e adicionaram-se $3,3 \mathrm{~g} \mathrm{~L}^{-1}$ da solução de uréia para o Latossolo Vermel ho Aluminoférrico e 2,5 $\mathrm{g} \mathrm{L}^{-1}$ para o L atossolo Vermelho distrófico. Após $1 \mathrm{~h}$ de incubação, acrescentaram-se $15 \mathrm{~mL}$ de solução de $\mathrm{KCl} 2 \mathrm{~mol} \mathrm{~L}^{-1}$, com 5 mg de acetato de fenil mercúrio; agitou-se por $5 \mathrm{~min}$ e procedeu-se à filtragem. No filtrado, realizou-se a determinação do teor de $\mathrm{N}$-amoniacal trocável, fazendo-se uso do método de destilação a vapor (Bremner \& Keeney, 1965). Para cada tratamento, executou-se um branco, da maneira acima descrita, porém adicionando-se a solução de uréia após a solução de $\mathrm{KCl}+$ acetato de fenil mercúrio. Do filtrado foram utilizados $10 \mathrm{~mL}$ para a destilação; em seguida, titulou-se com solução padronizada de ácido sulfúrico 0,001 $\mathrm{mol} \mathrm{L}^{-1}$.

O C-orgânico foi determinado pelo método descrito em Dabin (1976); oN total, segundo Ferreira et al. (1974) e Melo (1974). E ssas variáveis foram utilizadas para as correlações com a atividade da urease.

O clima da região é classificado, de acordo com o sistema de Koppen (Comissão de Solos do CNEPA, 1960), como sendo do tipo Cwa, ou seja, mesotérmico de inverno seco, em que a temperatura média do mês mais frio é inferior a $22^{\circ} \mathrm{C}$ e a do mês mais quente ultrapassa a $22^{\circ} \mathrm{C}$. O total de chuvas desse tipo cl imático varia de 1.100 a $1.700 \mathrm{~mm}$. O balanço hídrico da série J aboticabal (Aloisi \& Melo, 1971) revel ou que, durante os meses de dez./jan./fev./mar., há um adequado armazenamento deágua, acusando deficiências nos meses de abril a outubro.

Para comparação de médias, utilizou-se o teste deTukey a $5 \%$. Os resultados obtidos nas análises de N-total, C-orgânico e umidade foram utilizados para a obtenção das equações de regressão e para a determinação dos val ores de correlação entre esses parâmetros e a atividade da urease.

\section{RESULTADOS E DISCUSSÃO}

Os resultados obtidos para a variação sazonal na atividade da urease em amostras de LVaf e LVd, sob diferentes coberturas vegetais, encontram-sena figura la eb. NoLVaf (Figura 1a), ao seconsiderar as culturas isoladamente, notou-se que as de pinus e eucalipto apresentaram, de modo geral, maiores atividades ureolíticas que as demais. Esses resultados concordam com os obtidos por Pancholy 
\& Rice (1972), que observaram a influência do tipo e quantidade do material orgânico incorporado ao sol o na atividade da urease.

Nas culturas de milho e soja, observou-se um comportamento bastante semel hante entre elas e distinto das demais. A atividade enzimática foi baixa durante os meses de abril a outubro, aumentando a partir do mês de novembro, apresentando atividade enzimática máxima nos meses de dezembro e janeiro. No mês de dezembro, quando do plantio das culturas, a atividade da urease foi mai or do que nas culturas perenes, o que se deve, provavel mente, à adubação aplicada na instalação. Nos meses de dezembro e janeiro, ocorreram as condições ideais para a produção de fitomassa (disponibilidade de água e temperatura), o que levou também à maior incorporação de resíduos orgânicos ao solo, assim como de exudações radiculares.

Segundo Santos et al. (1991), a velocidade de hidrólise da uréia foi altamente alterada pelo tipo de vegetação, variando de $11,5 \mathrm{mg} \mathrm{N}-\mathrm{NH}_{4} \mathrm{~g}^{-1}$ sol o-1, no Latossolo Vermelho-Amarel o, a 71,4 mg N-NH ${ }_{4} \mathrm{~g}^{-1}$ solo $^{-1}$, no Latossolo Roxo sob vegetação de mata natural.

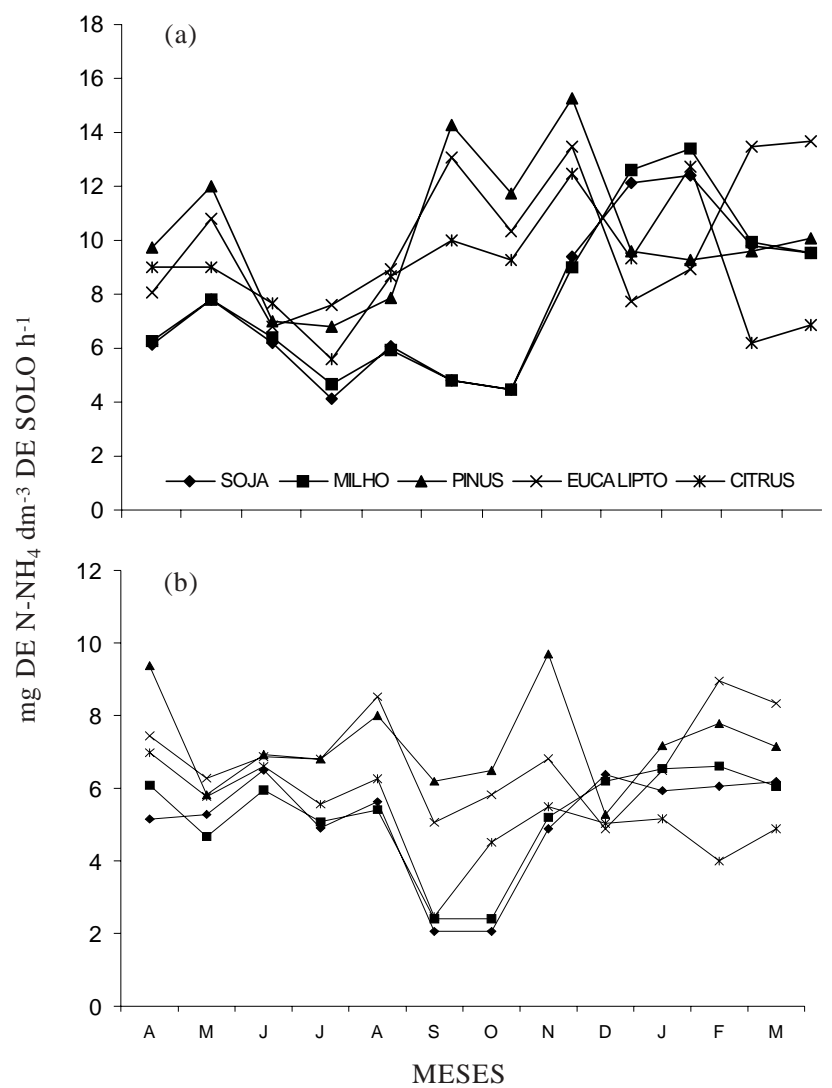

Figura 1. Velocidade de hidrólise da uréia (mg de $\mathrm{N}-\mathrm{NH}_{4}{ }^{+} \mathrm{dm}^{-3}$ solo ${ }^{-1}$ ) em amostras de L Vaf (a) e LVd (b) cultivadas com soja, milho, pinus, eucalipto e citrus, em função do tempo de amostragem.
Resultados similares foram obtidos por Palma \& Conti (1990) que observaram um aumento na atividade da urease nos meses de outubro a abril, em sol os sob a cultura de eucalipto, e nos meses de outubro a fevereiro, em sol os sob vegetação natural . Assim, pôde-se observar um aumento na atividade enzimática nos meses de verão, bem como diminuição nos meses de inverno. Ross et al. (1984) obtiveram baixa atividade da urease sob vegetação natural durante o inverno e Stott \& Hagerdorn (1980) encontraram altas atividades durante a primavera e verão e um declínio nos meses de inverno.

Analisando as amostras de LVd (Figuras 1b), verificou-se que as culturas de pinus e eucalipto também apresentaram, de modo geral, as mais altas atividades.

Portanto, a velocidade de hidrólise da uréia apresentou, de modo geral, uma diminuição a partir do mês de agosto, atingindo os menores val ores nos meses de setembro e outubro, havendo um aumento, a partir de então, para as culturas perenes, e, a partir de novembro, para as anuais. Os teores de Corgânico e $\mathrm{N}$-total tiveram um comportamento similar, porém diminuindo a partir de junho (Figuras 2 e 3).

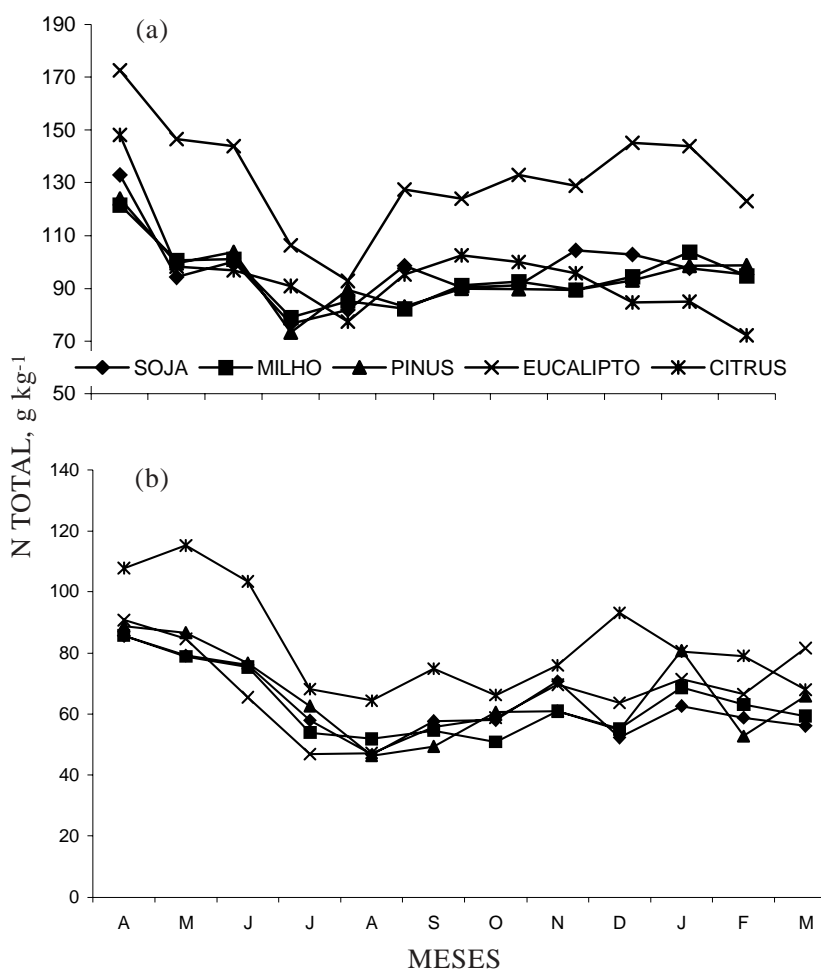

Figura 2. Nitrogênio total em amostras de LVaf (a) e LVd (b) cultivadas com soja, milho, pinus, eucalipto e citrus, em função do tempo de amostragem. 

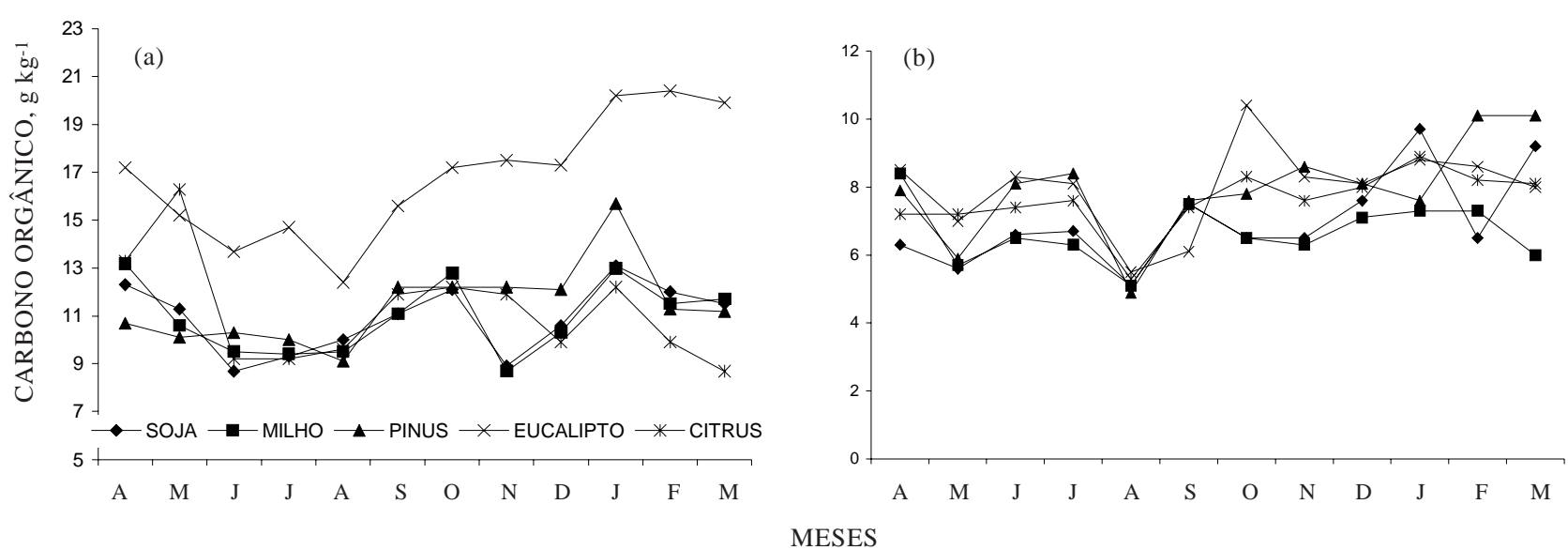

Figura 3. Carbono orgânico em amostras de LVaf (a) e LVd (b) cultivadas com soja, mi lho, pinus, eucalipto e citrus, em função do tempo de amostragem.

Quadro 2. Coeficientes de correlação entre atividade da urease, N-total, C-orgânico, pH e umidade

\begin{tabular}{lccrr}
\hline & F & Y & r & t \\
\hline U rease x N-total & $56,12 * *$ & $38,9721-0,3300 x$ & $-0,588$ & $-7,491^{* *}$ \\
Urease x C-org. & $61,12^{* *}$ & $2,6176+4,8617 x$ & 0,584 & $7,822^{* *}$ \\
Urease x umidade & $32,33^{* *}$ & $2,98134+0,3342 x$ & 0,464 & $5,686^{* *}$ \\
\end{tabular}

* e**: Significativos a 1 e $5 \%$, respectivamente.

Os resultados apresentados na figura 1 mostram um comportamento diferenciado entre os solos em relação à vel ocidade de hidrólise da uréia. A atividade da urease apresentou valores superiores em praticamente todas as épocas de amostragem (com exceção de abril, junho, julho e agosto) nas amostras de LVaf, as quais também apresentaram teores superiores de $\mathrm{N}$-total e C-orgânico (Figuras 2 e 3). Esses altos teores de N-total e C-orgânico podem ter produzido mudanças específicas na composição dos microrganismos do solo, causando as diferenças observadas na atividade enzimática.

A correlação entre urease e N-total (Quadro 2) mostrou-se negativa $(r=-0,58)$, enquanto entre urease e carbono orgânico e urease e umidade mostraram-se positivas $(r=0,58$ e $r=0,46$, respectivamente). Tais resultados divergem em relação ao nitrogêni o total eumidade dos resultados obtidos por Zantua \& Bremner (1977), Speir et al. (1980) e Dash et al. (1981), os quais constataram que a atividade da urease correlacionou-se positivamente com carbono orgânico e nitrogênio total. Dash et al. (1981) observaram correlação positiva entre atividade da urease e percentagem de silte e argila e negativa com pH e umidade.

\section{CONCLUSÕES}

1. A velocidade de hidrólise da uréia variou de acordo com a época de amostragem, apresentando valores mais elevados nos meses mais quentes e úmidos.

2. O tipo de cobertura vegetal alterou a atividade da urease quetendeu a ser mais el evada nas culturas permanentes não manejadas (pinus e eucalipto), embora, noinício do ciclo das culturas desoja e milho, a atividade da urease também tenha sido el evada.

\section{LITERATURA CITADA}

ARUNACHALAN, A. \& MELKANIA, N.P. Influence of soil properties on microbial populations, activity and biomass in humid subtropical mountains ecosystems of India. Soil Biol. Biochem., 30:217-223, 1999.

ALOISI, R.R. \& MELO, W.J . Balanço hídrico em J aboticabal. Método de Thornstwaite. In: CONGRESSO BRASILEIRO DE CIÊNCIA DO SOLO, 12., Vitória, 1971. Anais. Vitória, 1971. p.221-213. 
BENINI, S.; RYPNIEWSKI, W.R.; WILSON, K.S.,;MILLETI, S.; CIURLI, S. \& MORGANI, S. A new proposal for urease mechanism based on the crystal structures of native and inhibited enzyme from Bassillus pasteurii: why urea hydrolysis costs two nickels. Struct. Fold. \& Design, 7:205216, 1999.

BRASIL. Ministério da Agricultura. Centro Nacional de Pesquisas Agronômicas e Serviço Nacional de Pesquisas Agronômicas. Comissão de Solos. Levantamento de reconhecimento dos solos do Estado de São Paulo. Rio de J aneiro. CNEPA, 1960. 140p. (Boletim Técnico, 12)

BREMNER, J .M. \& KEENEY, D.R. Steam distillation methods for determination of ammonium, nitrate and nitriti. Anal. Chem. Acta, 32:485-495, 1965.

BREMNER, J.M. \& MULVANEY, R.L. Urease activity in soil. In: Soil enzymes. 1978. p.149.

CONRAD, J .P. Catalytic activity causing the hydrolysis of urea in soil as influenced by several agronomic factors. Soil Sci. Soc. Am. Proc., 5:238-241, 1940a.

CONRAD, J .P. The nature of the catalyst causing the hydrolysis of urea in soils. Soil Sci., 50:119-134, 1940b.

CONRAD, J.P. The occurrenceand origin of ureaselikeactivities in soil. Soil Sci., 54:357-380, 1942a

CONRAD, J.P. Enzymatic vs. microbial concepts of urea hydrolysis in soils. J. Agron., 34:1102-1113, 1942b.

CONRAD, J .P. Some effects of developing alkalinity and other factors upon urease like in soils. Soil Sci. Am. Proc., 5:171174, 1943.

DABIN, B. Curso sobrematéria orgânica do solo. Parte1. Análise dos compostos húmicos do solo. Piracicaba, CENA, 1976. p.115.

DASH, M.C.; MISHURA, P.C.; MOHANTY, R.K. \& BHATT, N. Effects of specific conductance and temperature on urease activity in some Indian soils. Soil Biol. Biochem., 13:73-74, 1981.

DENG, S.P. \& TABATABAI, M.A. Effect of tillage and residue management on enzymes activities in soils. Biol. Fert. Soil, 22:202-207, 1996.

EMPRESA BRASILEIRA DE PESQUISA AGROPECUÁRIA EMBRAPA. Centro Nacional de Pesquisa de Solos, Rio de J aneiro. Sistema Brasileiro de Classificação de Solos. Brasília, Embrapa produção de I nformação. Rio deJ aneiro: Embrapa Solos, 1999. 412p.

FERREIRA, M.E.; SOUZA, E.A.; TOLEDO J r., G.P.; KRONKA, S.N. \& ALOISI, R.R. Influência do selênio e do cobre na determinação do nitrogênio total de solos. In: ENCONTRO REGIONAL DA SBPC, J aboticabal, 1974. Anais. J aboticabal, 1974. p.56.

KLOSE, S. \& TABATABAI, M.A. Urease activity of microbial biomassa in soils. Soil Biol. Biochem., 31:205-211, 1999.

LONGO, R.M.; MELO, W.J .; PAVAN, S.A.; CHELLI, R.A. \& LEITE, S.A.A. Efeito da secagem ao ar, tempo e condições de armazenamento, concentração de uréia, temperatura, pH e tempo de incubação na atividade da urease em dois solos do Estado de São Paulo. In: CONGRESSO BRASILEIRO DE CIÊNCIA DO SOLO, 13., Porto Alegre, 1991. Anais. Porto Alegre, 1991. 89p.
LONGO, R.M.; MELO, W.J .; LEITE, S.A.S. \& CHELI, R.A. Variação anual da atividade da urease em amostras de Latossolo Roxo cultivado com pinus e soja. In: CONGRESSO BRASILEIRO DE ENGENHARIA AGRÍ COLA, 22., I lhéus, 1993. Anais. Ilhéus, 1993. p.23832389.

MAY, P.B. \& DOUGLAS, L.A. Assay for soil urease activity. Plant Soil, 45:301-305, 1976.

MELO, W.J . Variação do N-amoniacal e N-nirico em um Latossolo Roxo cultivado com milho (Zea mays L.) e com Lablab (Dolichos lablab). Piracicaba, Escola Superior de Agricultura "Luíz deQueiroz", 1974. 104p. (Tesede Doutorado)

OTOOLE, P.; MORGAN, M.A. \& MCALEESE, D.M. Effects of soil properties, temperature and urea concentration on patterns and rates of urea hydrolysis in some Irish soils. Irish J . Agric. Res., 21:185-197, 1982.

PALMA, M.P. \& CONTI, M.E. Urease activity in Argentine soils: field studies and influence of sample treatment. Soil Biol. Biochem., 22:105-107, 1990.

PANCHOLY, S.K. \& RICE, E.L. Effect of storage conditions on actives of urease, invertase, amylase and dehydrogenase in soil. Soil Sci. Soc. Am. Proc., 36:536-537, 1972.

RAIJ , B. van.; QUAGGIO,J .A.; CANTARELLA, H.; FERREIRA, M.E.; LOPES, A.S. \& BATAGLAI, OC. Análise química do solo para fins de fertilidade. Campinas, Fundação Cargil, 1987. 170p.

RODRIGUES, M.B. \& KIEHL, J.C. Volatilização de amônia após emprego de uréia em diferentes doses e modos de aplicação. R. Bras. Ci. Solo, 10:38-43, 1986.

ROTINI,O. T. La transformazions enzimatica dell-urea nell terreno. Ann. Labor. Ric. Ferm., 3:134-154, 1935.

ROSS, D.J .; SPEIR, T.W.; J ANINE, C.; COWLING, C. \& WHALE, K.N. Temporal fluctuations in biochemical properties of soil under pasture. II Nitrogen mineration and enzyme activities. Aust. J . Soil Res., 22:303-317, 1984.

SANTOS, A.R.; VALE, F.R. \& SANTOS, J .A.G. Avaliação de parâmetros cinéticos da hidrólise da uréia em solos do sul de Minas Gerais. R. Bras. Ci. Solo, 15:309-313, 1991.

SILVA, T.; MELO, W.J .; TEIXEIRA, S.T.; LEITE, S.A.S. \& CHELI, R.A. Efeito do lodo de esgoto contaminado com doses crescente de crômio sobre a atividade enzimática do solo. In: CONGRESSO BRASILEIRO DE CIÊNCIA DO SOLO, 15., Viçosa, 1995. Anais. Viçosa, Sociedade Brasileira de Ciência do Solo, 1995. p.2325-2330.

SPEIR T.W.; LEE, R.; PANSIER, E.A. \& CAIRNS, A. A comparation of sulfhatase, urease and protease actives in planted and in follow soils. Soil Biol. Biochem., 12:281-291, 1980.

STTOT, D.E . \& HAGEDORN, C. Interrelation between selected soil characteristics and arysulfatase and urease activities. Soil Sci. Plant Anal., 11:935-955, 1980.

ZANTUA, M.I. \& BREMNER, J .M. Stability of urease in soils. Soil Biol. Biochem., 9:135-140, 1977. 